\title{
Deflationism, Truth-Aptness and Non-Factualism
}

\author{
Massimiliano Vignolo \\ Department of Philosophy, University of Genoa
}

\begin{abstract}
I will argue that the standard formulation of non-factualism in terms of a denial of truth-aptness is consistent with a version of deflationsim. My line of argument assumes the use conception of meaning. This brings out an interesting consequence since mostly the philosophers who endorse the use conception of meaning, e.g. Paul Horwich, hold that deflationism is inconsistent with the strategy of implementing non-factualism in terms of a denial of truth-aptness and thereby urge a reformulation of non-factualism
\end{abstract}

Keywords: deflationism, non-factualism, use conception of meaning

\section{Introduction}

Ontological and epistemological considerations make some kinds of factse.g. ethical facts, aesthetic facts, modal facts, mathematical facts-seem weird and problematic to some philosophers. As a result, those philosophers attempt to avoid any commitment to such facts. Since facts are taken to be what sentences or propositions describe (or at worst misdescribe), one general form of response is to hold that sentences or propositions are not fact stating in those problematic regions of discourse. Nonfactualism is the view that sentences or propositions are not used to describe facts in certain regions of discourse. One standard strategy of implementing non-factualism is to deny that sentences or propositions are truth-apt in the problematic regions of discourse. The idea is that there is no reality behind our thought and talk, thereby no facts of the matter upon which the truth or falsity of our thoughts and sentences might depend. In other words, in the problematic regions of discourse the correctness of sentences or propositions does not consist in being true descriptions of any real aspect of the world.

Corresponding author's address: Massimiliano Vignolo, Department of Philosophy, University of Genoa, via Balbi 4, 16124 Genoa, Italy. Email: maxi@nous.unige.it. 
Horwich $(1990,2006)^{1}$ has claimed that deflationism is not consistent with the standard strategy of implementing non-factualism, because even in the disputed regions of discourse, sentences exhibit all the features of meaningful sentences. They possess standards of correctness and are embeddable in logical operations and indirect contexts. According to deflationism, to have these features is a sufficient condition for being truth-apt. As a result and contrary to the standard formulation of non-factualism, also those sentences should be counted as truth-apt.

In the same vein, Scott Soames (1997) has argued that the inconsistency with the standard strategy of implementing non-factualism is a consequence of any acceptable conception of truth, not only of deflationism. He illustrates the point by the following example of a hypothetical position that, he says, conflicts with deflationism. Take a philosopher who (i) holds that sentences like 'act A is wrong' in ethics are meaningful, (ii) is willing to assert some of these sentences, and (iii) denies that sentences are truth-apt in ethics. The philosopher will be disposed to assert sentences like

(a) John asserted 'act A is wrong'.

Given (ii), the philosopher will be disposed to assert sentences like

(b) Act $\mathrm{A}$ is wrong.

Given (iii), the philosopher will not be disposed to assert sentences like

(c) What John asserted-namely 'act A is wrong'-is true.

The philosopher's position certainly conflicts with deflationism, since, Soames says, acceptance of (a) and (b) commits one to accepting (c). But the fact that the premises (a) and (b) force the conclusion (c) has nothing specific to do with deflationism. Indeed, the conflict arises with all those conceptions of truth according to which all the instances of the disquotational schema (except those that are paradoxical or pathological) are true. In fact, from the truth of the instances of the disquotational schema, one who asserts (b) ought not to refuse to infer

$\left(b^{*}\right)$ 'Act A is wrong' is true

and he ought not to refuse to reach the conclusion

(c) What John asserted-namely 'act A is wrong'-is true

1 See also Boghossian (1990) for a similar argument. 
which contrasts with what the philosopher is willing to assert.

Soames concludes that the conflict arises with any reasonable conception of truth, since any reasonable conception of truth must acknowledge that all the instances of the disquotational schema (except those that are paradoxical or pathological) are true. So, if one is willing to assert $p$, then he ought not to refuse to give his assent to ' $p$ is true'. According to Soames, there is no special relationship between deflationism and non-factualism. Standard non-factualism is implausible in light of any reasonable conception of truth.

I will argue that Horwich is wrong, and a fortiori Soames is wrong too. My claim is that the standard strategy of implementing non-factualism is consistent with deflationism, or better with a version of deflationism, and a fortiori it is consistent with at least one conception of truth. In order to give support to my claim I will endorse Horwich's use conception of meaning. This brings out an interesting consequence. Indeed, Horwich suggests that we ought to reformulate non-factualism in order to avoid the contrast with deflationism. I will not be concerned with his proposed reformulation. Rather, I will follow the opposite strategy: to avoid contrast with nonfactualism we have to reformulate deflationism. I will show that a combination of the use conception of meaning, which Horwich professes, with a version of deflationism is compatible with the standard formulation of nonfactualism to the extent that a distinction can be laid down between genuine descriptions and sentences whose role is non-descriptive.

More specifically, I will argue that it is coherent for a speaker to accept the sentence $p$ without being committed to accepting the sentence ' $p$ is true', if $p$ does not have a descriptive role. This seems to impose at least a refinement of the view that all the instances of the disquotational schema are true. To make the point clearer, consider Soames' argument for the conclusion that the philosopher, who is willing to assert (a) and (b), must accept (c). My point is that Soames' claim that the instance of the disquotational schema

'act A is wrong' is true if and only if act A is wrong

is true begs the question at issue. ${ }^{2}$ The non-factualist philosopher envisaged by Soames might reply that all the instances of the disquotational schema ' $p$ ' is true if and only if $p$ are true on condition that the sentences that are substituted for the schematic letter $p$ are truth-apt. Likewise, one might take it for granted that the following inference schema is valid:

2 This point is stressed by Richard $(1997,63)$. 


$$
\begin{aligned}
& p \\
& \text { Therefore } \\
& ' p \text { ' is true. }
\end{aligned}
$$

The point is that to say that the premises of an inference entail its conclusion is to say that, necessarily, if the premises are true, then the conclusion is true as well. So, the non-factualist philosopher might (i) concede that the inference schema is valid and (ii) be willing to assert the premise 'act A is wrong' without being committed to the truth of the conclusion "'act $A$ is wrong" is true, since he does not agree that the premise is truth-apt.

I wish to make it clear that my aim in this paper is not to prove that nonfactualism is true in this or that region of discourse, but to show that the standard strategy of implementing non-factualism is a coherent philosophical view and consistent with deflationism. I concede that non-factualism might be false, or that there might be no good reasons for turning non-factualists, yet non-factualism is not incoherent.

Before going further, it will be helpful to sketch an example of the philosophical position I have in mind. Consider a philosopher who is willing to assert mathematical sentences, but does not admit numbers in his ontology. ${ }^{3}$ He utters mathematical sentences as disciplined by standards of correctness, and he is willing to reason from them, to embed them in logical operations and in indirect discourse, to argue that others ought to accept them. We can also think of his behaviour as being motivationally led by acceptance of mathematical sentences. For example, he refuses to pay the restaurant bill because he does not accept the sentence ' $9,50+8,50=19$ ' and wants to convince the waiter to accept the sentence ' $9,50+8,50=18$ '. ${ }^{4}$ In addition, suppose the philosopher in question endorses Horwich's conception of meaning. Then he will acknowledge that mathematical sentences are meaningful. He will also acknowledge that the acceptance of sentences acquires the psychological role that the states of belief ought to have. ${ }^{5}$ Then, the philosopher will agree that the cognitive states one is in while asserting mathematical sentences play the same motivational role as beliefs. However, the philosopher might insist that he does not admit numbers in his ontology and consequently that he is not committed to the truth-aptness of mathematical sentences. The philosopher denies that there is anything in the world in which the condition for the truth of mathematical sentences

3 Think, for example, of a nominalist philosopher who holds that although mathematical sentences do not describe any part of the world, they are necessary for shortening proofs in physics and other sciences.

4 This example is similar to one discussed by Richard $(1997,60)$.

5 Horwich tends to identify belief and acceptance of sentences. See, for example, Horwich (1991). 
consists, since he does not take numbers to be part of the world. There are no facts of the matter as to whether mathematical sentences are true or false. In sum, if $p$ is a mathematical sentence, the philosopher might be willing to assert $p$ but not ${ }^{\top} p$ is true'. For example, the philosopher will assert ${ }^{\prime} 9,50+$ $8,50=18^{\prime}$ in order to convince the waiter to withdraw the request for the bill to be paid, but he will not assert " $9,50+8,50=18$ " is true'.

My claim, then, is that this philosophical position combining Horwich's use conception of meaning with standard non-factualism is consistent with deflationism. In the next section, I will discuss two aspects of Horwich's conception of meaning that are relevant for my line of argument.

\section{Use and deflationsim}

I will argue that the use conception of meaning gives support to a version of deflationism that poses a constraint on the disquotational schema to such an extent that the sentences containing expressions lacking a truth-theoretic semantic value (i.e. objects for singular terms, $\mathrm{n}$-ary properties for $\mathrm{n}$-ary predicates; henceforth I will call such sentences "semantically defective") are not truth-apt, despite their meaningfulness and their being suitable for assertion. My claim is that, if $p$ is a sentence containing some empty expression, one can consistently assert $p$ and deny his assent to ' $p$ is true'.

In this section, I will appeal to Horwich's conception of meaning as a paradigm of the view that meaning properties are constituted by regularities of use. Specifically, I wish to underline two aspects of Horwich's view. The first is that it allows for a definition of synonymy and the second is that it offers a notion of meaning avoiding any truth-theoretic notions. In the next section, I will employ both aspects to present a version of deflationism that, I claim, is consistent with the standard formulation of non-factualism.

According to Horwich's use conception of meaning, the property of having a certain meaning is constituted by the property of being governed by certain basic and explanatorily fundamental patterns of use. In general, for each expression $w$ there is a regularity of the form

All uses of $w$ stem from its possession of the acceptance property $\mathrm{A}(w)$, where $\mathrm{A}(w)$ specifies the circumstances in which certain sentences containing $w$ are accepted. ${ }^{6}$

${ }^{6}$ For example: The acceptance property that governs a speaker's overall use of 'and' is his tendency to accept ${ }^{\ulcorner} p$ and $q^{\top}$ if and only if he accepts both, ' ${ }^{\top} p$ and ' $q$ '. 'red"s meaning stems from our underived propensity to accept 'that is red' in response to the sort of visual experience normally provoked by observing a clearly red surface. Cf. Horwich $(1998,45)$. According to Horwich (2004), the meaning constitutive regularities of use are individuated as those regularities which play a basic and explanatorily fundamental role with respect of 
One might think that a definition of synonymy can be extracted from this conception of meaning.

For any $L, L *, x, y$ ( $x$ in $L$ is synonymous with $y$ in $L *$ if and only if the overall use of $x$ in $L$ is governed by the same acceptance properties as the overall use of $y$ in $L *$ ).

As it stands, this definition does not work. It has been argued ${ }^{7}$ that there are no acceptance properties that are constitutive of the meanings of compound expressions. If there were, they ought to be compositional, but acceptance properties of compound expressions are not compositional. In order to cope with this difficulty, Horwich (2005) suggests distinguishing two orders of facts that are constitutive of meaning properties. Meaning properties of simple expressions are constituted by facts concerning their acceptance properties. Meaning properties of compound expressions are constituted by the fact that they are composed in accordance with certain syntactic structures from simple expressions having certain acceptance properties. Following Horwich's suggestion, we might distinguish two definitions of synonymy, one for simple expressions and the other for compound expressions (' $S_{L}(x)$ ' means that $x$ is a simple expression of $L$ and ' $C_{L}(x)$ ' means that $x$ is a compound expression of $L$ ):

(1) For any $L, L *, x, y$ (if $S_{L}(x)$ and $S_{L *}(y)$ then $(x$ in $L$ is synonymous with $y$ in $L *$ if and only if the overall use of $x$ in $L$ is governed by the same acceptance properties as the overall use of $y$ in $L *)$ ).

(2) For any $L, L *, x, y$ (if $C_{L}(x)$ and $C_{L *}(y)$ then ( $x$ in $L$ is synonymous with $y$ in $L *$ if and only if $x$ has the same syntactic structure as $y$ and the overall use of each simple component of $x$ in $L$ is governed by the same acceptance properties as the overall use of the corresponding simple component of $y$ in $L *)$ ).

The other aspect of Horwich's view I wish to underline is the idea that truththeoretic notions are not constitutive of meaning. Horwich's view is that linguistic competence is constituted by (implicit) knowledge of regularities of use of linguistic expressions. So, the theory that describes the meaning constitutive patterns of use is still taken as a theoretical representation of linguistic competence. But a theory of meaning inspired by Horwich's use conception describes the patterns of use that are meaning-constitutive without employing truth-theoretic notions. Horwich $(1998,73)$ holds that a sentence's truth condition is a consequence of its meaning, not constitutive of

the overall usage of expressions and such that (expert) speakers conform to them without needing or even having the possibility of a justification.

7 See Fodor and Lepore (1991, 1996). 
it. Specifically, our knowledge of a sentence's truth condition is the product of (i) our knowledge of its meaning and (ii) our knowledge of a deflationary theory of truth-theoretic notions. Together they allow for the derivations of the instances of the T-schema. In so far as we understand all the constituents of the instances of the T-schema, we can be said to know what they state, namely the representational link between language and world.

I will appeal to the two aspects of Horwich's conception of meaning just discussed, namely the fact that it provides an account of synonymy and the fact that it avoids truth-theoretic notions, for presenting a deflationary view of truth that is compatible with the standard formulation of non-factualism, according to which semantically defective sentences are not truth-apt and do not qualify as fact stating. The approach I will present is a modified version of the Tarskian theory of truth. Moreover, I will argue that such approach qualifies as deflationary. First, I will show that the use conception of meaning is suitable for defending the Tarskian conception of truth. Then, I will maintain that the modified Tarskian theory provides an account of truth that restricts the validity of the instances of the disquotational schema to sentences that are not semantically defective. So that if $p$ is a semantically defective sentence, one can consistently give his assent to $p$ but not to ${ }^{\circ} p$ is true?.

Convention $\mathrm{T}$ says that we need to define truth in $\mathrm{L}$ in such a way that the sentences of the metalanguage in the right-hand side of T-sentences must be the translation of the sentences of the object-language in the left-hand side. The notion of translation presupposes the notion of meaning. We cannot speak of translation without speaking of correctness of translation, and a translation is correct if and only if it is meaning preserving. It appears that if we have to rely on the notion of meaning in fixing the condition of material adequacy for theories of truth, we cannot accept a notion of meaning spelled out in terms of truth-conditions. It would be circular to use the notion of meaning to construct an account of truth in $\mathrm{L}$ and at the same time to cash the notion of meaning in terms that require an account of truth in L. We can point out the circularity by the following reasoning. ${ }^{8}$

Convention $\mathrm{T}$ states that it is a sufficient condition for an account of truth to be materially adequate that it implies T-sentences in which the metalanguage sentences in the right-hand side are the translations of the objectlanguage sentences in the left-hand side. Hence, Convention T uses the twoplace meta-metalinguistic predicate ' $x$ is equivalent in meaning to $y$ ', where ' $x$ ' ranges over the sentences of the object-language and ' $y$ ' over the sentences of the metalanguage. But how should we explain the relation of being equivalent in meaning? Any explanation according to which $x$ is equiva-

\footnotetext{
${ }^{8}$ I borrow this argument from Patterson (2002).
} 
lent in meaning to $y$ if and only if $x$ and $y$ are true under the same conditions would require that we already possess a truth predicate for the objectlanguage and the metalanguage in a meta-metalanguage. But if we are able to define truth in L in a meta-metalanguage, then we can already define it in a metalanguage, since the meta-metalanguage is a metalanguage. Therefore, Convention T would state what is needed to define truth in $\mathrm{L}$ in a metalanguage only by assuming that we are already able to define it in another metalanguage. If this were the correct interpretation of Convention $\mathrm{T}$, then any account of truth that is accepted insofar as it satisfies Convention $\mathrm{T}$ would be deprived of its philosophical import. The account of a given notion preserves its interest only if it does not presuppose the availability of another account of the same notion. The upshot is that we cannot be content with an account of truth for the reason that it is constructed in accordance with Convention $\mathrm{T}$ and at the same time maintain that the notion of meaning has to be explained in terms of truth-conditions.

The conclusion is that Convention $\mathrm{T}$ not only requires the notion of meaning, but also presupposes a conception of meaning other than the truththeoretic one. An alternative is to endorse some version of the use conception of meaning like Horwich's. In the next section, I will sketch the guidelines of a deflationary theory of truth that is consistent with the standard formulation of non-factualism and based on the use conception of meaning.

\section{A deflationary account of truth}

It remains to be shown that we can construct a theory of truth according to which semantically defective sentences are not truth-apt. The idea is to present a theory that allows for truth-value gaps. The view that there are truth-values gaps is not a novelty. Gottlob Frege (1982) suggested that sentences containing expressions without referents express propositional contents but do not possess any truth-value. Saul Kripke (1975) uses truth-value gaps to provide a solution to the Liar Paradox. Scott Soames (1999) himself embraces a similar solution. My proposal is to appeal to a modified Tarskian theory of truth in L. First, I will sketch the guidelines of such theory and then I will explain in which sense it qualifies as a modified Tarskian theory of truth in $L$ that retains a deflationary nature.

Let $\mathrm{L}$ be a fragment of English containing (i) singular terms, (ii) monadic predicates and (iii) negation, conjunction and disjunction. The modified Tarskian theory of truth in L can be sketched as follows: ${ }^{9}$

9 Of course, my sketch leaves a lot of work to be done. Here, for the sake of exposition, I follow Soames' (1984) very simplified presentation of the Tarskian theory of truth in L. 
Definition of reference:

For any singular term $n$ of $\mathrm{L}$ and object $o, n$ refers in L to $o$ if and only if $n=$ 'London' and $o=$ London or...

Definition of ascription:

For any predicate $G$ of $\mathrm{L}$ and property $P, G$ ascribes in $\mathrm{L} P$ if and only if $G=$ 'is a capital' and $P=$ the property of being a capital or...

Definition of application:

For any predicate $G$ of $\mathrm{L}$, any object $o, G$ applies in $\mathrm{L}$ to $o$ if and only if $G=$ 'is a capital' and $o$ is a capital or...

Definition of truth-aptness:

For any sentence $S$ of $L, S$ is truth-apt if and only if $S=G n$ for some singular term $n$ and monadic predicate $G$ and there are exactly one object $o$ referred to by $n$ and one property $P$ ascribed by $G$ or

$S=\sim A$ and $A$ is truth-apt or

$S=A \wedge B$ and $A$ is truth-apt and $B$ is truth-apt or

$S=A \vee B$ and $A$ is truth-apt and $B$ is truth-apt.

Definition of truth:

For any sentence $S$ of $\mathrm{L}, S$ is true in $\mathrm{L}$ if and only if $S=G n$ for some singular term $\mathrm{n}$ and monadic predicate $G$ and $S$ is truth-apt and $G$ applies to the object referred to by $n$ or $S=\sim A$ and $S$ is truth-apt and $A$ is false or

$S=A \wedge B$ and $S$ is truth-apt and $A$ is true and $B$ is true or $S=A \vee B$ and $S$ is truth-apt and $A$ is true or $B$ is true.

Definition of falsity:

For any sentence $S$ of $\mathrm{L}, S$ is false in $\mathrm{L}$ if and only if $S=G n$ for some singular term $n$ and monadic predicate $G$ and $S$ is truth-apt and $G$ does not apply to the object referred to by $n$ or $S=\sim A$ and $S$ is truth-apt and $A$ is true or $S=A \wedge B$ and $S$ is truth-apt and $A$ is false or $B$ is false or $S=A \vee B$ and $S$ is truth-apt and $A$ is false and $B$ is false.

It avoids quantifiers and sequences and employs the notion of application instead of the notion of satisfaction. I take technicalities not to add any substantial aspect to the main point of the Tarskian approach, which is the definition of primitive semantic notions by lists. 
Finally, we can state a definition of factuality:

For any sentence $S$ of $\mathrm{L}, S$ is factual if and only if it is truth-apt.

Some comments are in order. First, the theory defines two sets of sentences, those that are true and those that are false. These sets are mutually exclusive but not jointly exhaustive. Semantically defective sentences-sentences containing singular terms that do not refer to anything or predicates that do not ascribe any property-are not truth-apt and thereby are truth-valueless. Second, I endorse the view that properties are the truth-theoretic semantic values of predicates and that predicates stand in the semantic relation of ascription ${ }^{10}$ to properties. This view is needed to provide standard nonfactualists with the resources for a global strategy for supporting their position. Indeed, standard non-factualists deny that the sentences in a given disputed region of discourse are truth-apt since they deny that there are facts that make them true or false. So, the reason why a sentence is not truth-apt is that it is semantically defective, in the sense that some of its parts do not have any truth-theoretic semantic value. The point is that endorsing standard non-factualism in certain regions of discourse seems to require that predicates have properties as truth-theoretic semantic values. Think of sentences in aesthetics, like 'rhubarb is delicious'. The only plausible way to regard the sentence 'rhubarb is delicious' as semantically defective is to take 'is delicious' as a predicate that does not ascribe any property, given that certainly 'rhubarb' does have a truth-theoretic semantic value. The core of non-factualism in aesthetics is that there are no aesthetic properties. That is the reason why 'is delicious' does not ascribe any property and 'rhubarb is delicious' is semantically defective. In general, as we are trying to explain non-factuality of sentences by means of their being semantically defective, we need to recognise truth-theoretic semantic values of predicates in order to give non-factualism a formulation that can be extended to all regions of discourse.

The third comment is about the enumerative definitions of reference, ascription and application. In this respect we can say that the proposed theory of truth in L is Tarskian in spirit. It avoids conceptual analysis and reduction of primitive semantic notions. Moreover, the criterion that underlies the construction of the definitions of reference, ascription and application is guided by the same principle underlying Convention $\mathrm{T}$. The principle that guides the matching of the expressions of the object-language to the expressions of the metalanguage is sameness of meaning. For instance, we can state

${ }^{10}$ I borrow the notion of ascription from Wright (1998). Wright holds that properties can be both referred to by singular terms like 'the property of being a dog' and ascribed by predicates like 'is a dog'. 
that 'London' refers in L to London because 'London' in L (the fragment of English in our example) has the same meaning as 'London' in the metalanguage (English in our example). Mainly, it is this enumerative characteristic that preserves the deflationary nature of the modified Tarskian theory of truth in $\mathrm{L}$.

The enumerative characteristic notwithstanding, we can imagine someone accusing my proposal of not being deflationary and presenting the following rejoinder. If non-factualism is a matter of semantic defectiveness, then what determines whether all parts of a sentence have truth-theoretic semantic values or not? If it is something of robust, such as a causal factor, then it becomes difficult to view the resulting account of truth as deflationary. On the other hand, if having a semantic value is an appropriately thin matter, then what meaningful sentences would turn out to be semantically defective?

I reply to this objection as follows. First, it is worth nothing that although deflationism does not hold that truth consists in correspondence to facts, it does not need to deny the view that truths correspond to facts. As Horwich (1990, ch. 7) points out, the reasoning that leads to correspondence starts with the innocuous idea that whenever a sentence or a proposition is true, they are true because matters in the world stands in certain ways, and matters in the world are usually something external to sentences and propositions. For example, we wish to say that

'snow is white' is true because snow is white

in other words

the fact that snow is white makes the sentence 'snow is white' true.

These remarks, Horwich says, are totally coherent with deflationism. Indeed, from our knowledge and theories of the world we can deduce, and thereby explain, that

snow is white

and from the corresponding instance of the disquotational schema we can deduce, and thereby explain

'snow is white' is true.

Therefore, the explicative dependence of truths upon facts is preserved within deflationism: snow's being white explains the truth of 'snow is white. According to Horwich, then, deflationism does not reject the view that truths correspond to facts, but only the stronger view that truth consists in such correspondence. 
I contend that we can provide an explanation of the semantic defectiveness of sentences similar to the explanation, which Horwich suggests, of the dependence of truths upon facts. The idea is that non-factualist philosophers can deduce (i) that objects or properties of certain kinds do not exist from their favourite picture of the world, (ii) that certain expressions do not have truth-theoretic semantic value from the definitions of reference and ascription and (iii) that the sentences that contain those expressions are semantically defective. For example, the philosopher who takes a non-factualist position in aesthetics can deduce that aesthetics properties do not exist from his preferred metaphysics. From this, he can deduce, say, that

the property of being delicious does not exist.

Then, from the definition of ascription, he can deduce that

'is delicious' does not ascribe any property.

Finally, he can deduce that

'rhubarb is delicious' is semantically defective.

This model of explanation does not assume any inflationary view of semantic notions. We do not need anything of robust in order to say what determines whether all parts of a sentence have truth-theoretic semantic values or not.

Before closing this section, I want to address two further objections that might be raised against my proposal. One objection is that my proposal is not consistent with the use conception of meaning. Is not the use conception committed to the view that all the instances of the disquotational schema are constitutive of the meaning of the predicate 'true'? In my view, the route for replying to this objection is to keep distinct the account of the concept of truth from the account of the property of truth.

It might be conceded that normal speakers, who possess the concept of truth but are not experts, or philosophers, have the disposition to accept all the instances of the disquotational schema, even those that are paradoxical, pathological or semantically defective. In other words, it might be conceded that this regularity of use is constitutive of the mastery of the concept of truth. On the other hand, it should be recognised that this disposition to use the truth predicate has to be regimented by the theory of the property of truth. After all, there is common agreement that whatever Tarski was attempting by his theory of truth in L, he was not giving the analysis of the concept of truth in $\mathrm{L}$ and he was not looking for an expression synonymous with 'truth in L' either. ${ }^{11}$ Although we cannot take the Tarskian theory to

\footnotetext{
${ }^{11}$ For a discussion of this point see Kirkham (1995, ch. 6).
} 
offer an analysis of the concept of truth in L or of the meaning of 'true in L', we can still regard it as a theory of the property of truth in L.

Besides, even the claim that competent speakers manifest the tendency to accept all the instances of the disquotational schema is not as solid as it might appear. Maybe they have such tendency when they are in an unreflective mood. However, it does not take very long to disclose the semantic paradoxes to competent speakers or to make their intuitions vacillate asking them whether it is really true that Santa Claus wears a red suit. The advantage of a theory of the property of truth in $\mathrm{L}$ as distinct from an account of the mastery of the concept of truth in $\mathrm{L}$ is that it provides a way for regimenting the dispositions of speakers. But this aspect need not be in contrast with the view that speakers' dispositions are constitutive of the mastery of concepts (meanings).

The other related objection is the following. The truth predicate functions as a device for endorsing (i) assertions of sentences whose content might be unspecified and (ii) assertions of whole classes of sentences, as when one asserts 'what John will assert tomorrow is true' or 'everything John asserts is true.' If non-factualists do not apply the truth predicate to sentences in certain regions of discourse they will lack a device for endorsing both the assertion of the sentences in those regions whose content they are not able to specify and the assertion of whole classes of sentences. My reply to this objection is that from the premise that the truth-predicate is not available to non-factualists as a device for endorsing assertions in certain regions of discourse, the conclusion does not follow that non-factualists do not have any other device for endorsing such assertions. It has been argued ${ }^{12}$ that 'true' and 'warrantedly assertible' have the same positive normative force: any reason to regard a sentence as warrantedly assertible is a reason to endorse the assertion of the sentence. Then, non-factualists can identify the correctness of sentences in non-factual regions of discourse with the notion of warranted assertibility or a notion characterised in terms of warranted assertibility, like for example the notion of superassertibility. ${ }^{13}$ They can employ such notion to state the following schema:

If $\left.{ }^{\ulcorner} p\right\urcorner$ is warrantedly assertible (superassertible), then $p$

Instances of the schema might be used to form arguments like the following:

Everything John asserts is warrantedly assertible (superassertible). John asserts 'act A is wrong'.

${ }^{12}$ Cf. Wright $(1992,18)$.

${ }^{13}$ I borrow the notion of superassertibility from Wright (1992), although Wright proposes superassertibility as a notion of truth. 
Therefore

act $\mathrm{A}$ is wrong.

In conclusion, non-factualists can employ a predicates like 'warrantedly assertible' or 'superassertible' as a device for endorsing assertions of semantically defective sentences and restrict the application of 'true' to sentences that are fact stating.

In the following section, I will address some objections to the Tarskian theory of the property of truth in L. I take such objections to be relevant to the discussion in this paper not only because they threaten directly the Tarskian approach and the version of deflationism that I have been arguing for is a modified Tarskian theory, but also because my replies to them will reveal the fundamental role that the use conception of meaning plays in my defence of the claim that standard non-factualism is consistent with deflationism.

\section{Further objections and replies}

The literature offers several arguments against the Tarskian theory of truth in L. In this section, I will consider some of them. The role of the use conception of meaning will turn out fundamental in my replies. There are three main objections to the Tarskian theory of truth in $\mathrm{L}^{14}$

(1) The Tarskian truth predicates and the ordinary truth predicate have different modal properties, even when the ordinary truth predicate is restricted to particular languages. ${ }^{15}$

(2) The Tarskian truth predicates differ in meaning from the ordinary truth predicate, even when the ordinary truth predicate is restricted to particular languages. ${ }^{16}$

(3) The ordinary notion of truth can play a substantial role in theories of meaning, whereas the Tarskian notion of truth cannot.

Objection (1) holds that the ordinary truth predicate and the Tarskian truth predicates have different modal properties. We can reconstruct the objection in the following way: for the sake of exposition imagine a language L containing only two sentences: 'Der mond ist blau' and 'Der Schnee ist weiss'. The Tarskian definition of truth in $\mathrm{L}$ can be simplified by specifying enumeratively what it is for each sentence to be truth:

${ }^{14}$ Cf. Soames $(1997,22)$.

${ }^{15}$ Etchemendy (1988), Putnam (1994) and Soames (1997) raise this objection.

${ }^{16}$ Soames (1997) and Künne $(2003,224)$ raise this objection. 
(a) For any $x$ ( $x$ is true in L if and only if ( $x=$ 'Der mond ist blau' and the moon is blue) or ( $x=$ 'Der Schnee ist weiss' and snow is white) $))$.

If we consider the sentence 'Der Schnee ist weiss', from (a) we obtain:

(b) 'Der Schnee ist weiss' is true in L if and only if (('Der Schnee ist weiss' = 'Der Mond ist blau' and the moon is blue) or ('Der Schnee ist weiss' $=$ 'Der Schnee ist weiss' and snow is white)).

The right-hand side of (b) is logically equivalent to the sentence 'snow is white. Therefore, the sentence 'Der Schnee ist weiss' satisfies the Tarskian truth predicate, in every possible world in which snow is white. However, the objection goes, the sentence 'Der Schnee ist weiss' satisfies the ordinary truth-predicate, even in those possible worlds in which it means, say, that water is liquid and water is liquid and snow is not white. And it is not true in those possible worlds in which it means, say, that the earth is cubical and the earth is not cubical and snow is white.

My claim is that objection (1) rests on (i) a misunderstanding of the Tarskian theory and (ii) the assumption that the ordinary truth predicate is defined over strings of sounds/marks, which are individuated in virtue of their phonological, morphological and syntactical characteristics. I will argue that such assumption begs the question against the use conception of meaning.

(i) The Objection overlooks the fact that the Tarskian theory gives an absolute definition of truth in $\mathrm{L} .{ }^{17}$ One of the essential features of the Tarskian theory is that the meanings of the expressions of $\mathrm{L}$ are taken as fixed. The possible worlds in which, say, 'Der Schnee ist weiss' means that water is liquid and water is liquid and snow is not white are not possible worlds in which 'Der Schnee ist weiss' does not satisfies the Tarskian truth predicate. Those are worlds in which speakers do not speak L, since they use the string of sounds/marks 'Der Schnee ist weiss' with a different meaning from the meaning it has in L. The point is that the Tarskian theory does not give the account of truth for mere strings of sounds/marks, which are individuated only in virtue of their phonological, morphological and syntactic characteristics. Rather, it gives the account of truth for expressions, which are strings of sounds/marks endowed with their meanings. The claim, then, is that semantic properties are essential properties of linguistic expressions, whereas they cannot be essential properties of strings of sounds/marks. There are no possible worlds in which the expressions of a language have semantic properties different from the semantic properties they have in the actual world,

${ }^{17}$ See for example Künne (2003, 220-221), Patterson (2002, 2003), Carpintero (1996) and Davies (1981, 28). 
although there might be possible worlds in which different languages, with different expression, are spoken.

(ii) One might try to renew the objection by claiming that we need to define truth over strings of sounds/marks, which are individuated only in virtue of phonological, morphological and syntactic characteristics. This claim assumes that semantic properties call for an explanation other than the account provided by the Tarskian theory. This explanation should be the product of empirical investigation. Perhaps semantic properties need to be explained through a physicalistic reduction. In this sense, the objection seems to be reduced to the claim that an account of semantic properties that does not make them vary from one possible world to another in accordance with the change of speakers' linguistic behaviour, is bound to fail. My reply to this claim is that the view that the semantic properties of the expressions of a language vary from one possible world to another in accordance with speakers' linguistic behaviour takes it for granted that a theory of truth must address the following question: ${ }^{18}$

(Q) In virtue of what facts regarding speakers' linguistic behaviour do the emissions of certain strings of sounds/marks have the property of truth?

The answer, then, is to be discovered by empirical investigation. However, according to my picture, a theory of truth need not be taken to address the question (Q). Rather, it should be taken to answer the following question:

$\left(\mathrm{Q}^{*}\right)$ What are the semantic properties of the expressions of $\mathrm{L}$ ?

Certainly, to answer this question we need to investigate L-speakers' linguistic behaviour. Yet, the investigation of linguistic behaviour comes into play at the level of the identification of the language spoken and, more precisely, of the meanings of the strings of sounds/marks uttered. Thus, empirical investigation comes into play to answer the question:

$\left(\mathrm{Q}^{* *}\right)$ In virtue of what facts regarding speakers' linguistic behaviour do certain strings of sounds/marks have certain meanings?

In order to answer question $\left(\mathrm{Q}^{* *}\right)$ in accordance with the use conception of meaning we do not need any reductive analysis of truth-theoretic semantic notions, because, as we said in section 2, a theory of meaning inspired by the use conception does not employ truth-theoretic notions. In conclusion, objection (1) works on the assumption that the ordinary truth predicate is defined not over expressions, which are individuated in virtue of their

${ }^{18}$ Soames (1984) himself makes the distinctions between $(\mathrm{Q})$ and $\left(\mathrm{Q}^{*}\right)$ and says that a Tarskian theory of truth in $\mathrm{L}$ addresses question $\left(\mathrm{Q}^{*}\right)$. 
meanings and carry their semantic properties essentially, but over strings of sounds/marks, which are individuated in virtue of their phonological, morphological and syntactic characteristics. However, the rationale for making that assumption begs the question against the use conception of meaning.

Objection (2) says that the ordinary predicate 'true in L' (that is the ordinary truth predicate restricted to the sentences of a given language $\mathrm{L}$ ) and the Tarskian truth predicates are epistemically different. For the sake of exposition, let us deal again with a language $L$ containing only two sentences: 'Die Erde bewegt sich' and 'Der Mond ist rund'. As in the previous case, we can specify enumeratively what it is for each sentence to be true:

(c) For any $x$ ( $x$ is true in L if and only if ( $x=$ 'Die Erde bewegt sich' and the earth moves) or ( $x=$ 'Der Mond ist rund' and the moon is round))).

Now, compare the following two sentences:

(d) 'Der Mond ist rund' is true in L if and only if the moon is round and

(e) (('Der Mond ist rund' = 'Die Erde bewegt sich' and the earth moves) or ('Der Mond ist rund' = 'Der Mond ist rund' and the moon is round)) if and only if the moon is round.

(e) is obtained by substituting " Der Mond is rund" is true in L' in (d) with the definiens we get from (c).

The objection is that (d) and (e) have different epistemic properties, since the knowledge of (d) is sufficient to justify the belief that the sentence 'Der Mond ist rund' does not mean that the earth moves. By contrast, the knowledge of (e) does not give any information about the meaning of that sentence. The conclusion is that the ordinary truth predicate and the Tarskian truth predicates are epistemically different, since the former can justify beliefs about the meanings of sentences, whereas the latter cannot.

My reply to objection (2) is that it assumes, like in objection (1), that the Tarskian truth predicates are defined over strings of sounds/marks. It overlooks that (e) is derived from (c) and that if one understands (c) as the Tarskian account of truth in L, which is a necessary condition for deducing (e), then he will know that 'Der Mond ist rund' means that the moon is round and does not mean that the earth moves, because variables in (c) range over sentences endowed with their meanings. In other words, in order to formulate and understand (c) as the Tarskian account of truth in L, one needs to know that 'Der Mond ist rund' means that the moon is round, since he needs (i) to know that the object-language sentence 'Der Mond ist rund' 
is correctly translated into the metalanguage sentence 'the moon is round' and (ii) to understand the metalanguage sentence 'the moon is round'.

I take objection (3) simply to beg the question against the philosophical position that combines the Tarskian approach to truth with the use conception of meaning. As argued in section 2, the Tarskian theory of truth in L requires the notion of meaning. On pain of circularity, that notion cannot be the truth-theoretic one. Therefore, the conclusion that the Tarskian notion of truth cannot have any theoretical role in theory of meaning by itself does not undermine the Tarskian approach. Certainly, we should agree on the conditional claim that if the notion of truth really is required in theory of meaning, then the Tarskian theory cannot be taken as an adequate account of truth. But advocates of the use conception of meaning take the antecedent of the conditional to be false.

\section{Conclusions}

I argued that the standard formulation of non-factualism is consistent with deflationism, in contrast to the view held by some philosophers who are deflationists and urge a reformulation of non-factualism.

The version of deflationism I presented in a sketch is a modified Tarskian theory of truth in $\mathrm{L}$ that allows for truth-value gaps. Semantically defective sentences are neither true nor false and do not have a descriptive role. I argued that such theory is Tarskian and deflationary because it proceeds by enumerative definitions and avoids conceptual analysis or reduction of primitive semantic notions.

The defence of my claim assumed the use conception of meaning. This brought out an interesting consequence, because many of those philosophers who call for a reformulation of non-factualism embrace the use conception of meaning, i.e. Paul Horwich. The use conception of meaning turned out fundamental since (i) it provides an account of synonymy and (ii) avoids truth-theoretic notions. These aspects are important because the Tarskian approach requires the notion of sameness of meaning that, on pain of circularity, cannot be based on the truth-theoretic conception of meaning. The use conception of meaning turned out fundamental also in replying to some widespread objections to the Tarskian approach.

\section{Bibliography}

Boghossian, P. (1990). The status of content, Philosophical Review 99: 157184 . 
Carpintero, M. G. (1996). What is a tarskian definition of truth?, Philosophical Studies 82: 113-144.

Davies, M. (1981). Meaning, Quantification, Necessity, Routledge and Kegan, London.

Etchemendy, J. (1988). Tarski on truth and logical consequence, Journal of Symbolic Logic 53: 51-79.

Fodor, J. and Lepore, E. (1991). Why meaning (probably) isn't conceptual role, Mind and Language 6: 329-343.

Fodor, J. and Lepore, E. (1996). The pet fish and the red herring: Why concepts aren't prototypes, Cognition 58: 243-276.

Frege, G. (1982). Über Sinn und Bedeutung, Zeitschrift für Philosophie und Philosophische Kritik 100: 22-50.

Horwich, P. (1990). Truth, Blackwell, Oxford.

Horwich, P. (1991). On the nature and norms of theoretical commitment, Philosophy of Science 58: 1-14.

Horwich, P. (1998). Meaning, Clarendon Press, Oxford.

Horwich, P. (2004). A use theory of meaning, Philosophy and Phenomenological Research 68: 351-372.

Horwich, P. (2005). Deflating compositionality, Reflections on Meaning, Clarendon Press, Oxford, pp. 198-221.

Horwich, P. (2006). A world without isms, in P. G. M. P. Lynch (ed.), Truth and Realism, Oxford University Press, Oxford, pp. 188-202.

Kirkham, R. (1995). Theories of Truth, MIT Press, Cambridge, Mass.

Künne, W. (2003). Conceptions of Truth, Clarendon Press, Oxford.

Kripke, S. (1975). Outline of a theory of truth, The Journal of Philosophy 72: 690-716.

Patterson, D. (2002). Theories of truth and convention T, Philosopher' Imprint 2: 1-16.

Patterson, D. (2003). What is a correspondence theory of truth?, Synthese 137: 421-444.

Putnam, H. (1994). Words and Life, Harward University Press, Cambridge, Mass, chapter On Truth, pp. 315-329.

Richard, M. (1997). Deflating truth, Philosophical Issues 8: 57-78.

Soames, S. (1984). What is a theory of truth?, The Journal of Philosophy 81: 411-429. 
Soames, S. (1997). The truth about deflationism, Philosophical Issues 8: 1-44. Soames, S. (1999). Understanding Truth, Oxford University Press, Oxford.

Wright, C. (1992). Truth and Objectivity, Harvard University Press, Cambridge, Mass.

Wright, C. (1998). Why Frege did not deserve his Granum Salis. A note on the paradox of 'the concept horse' and the ascription of bedeutungen to predicates, Grazer Philosophische Studien 55: 239-263. 